http://jmscr.igmpublication.org/home/

ISSN (e)-2347-176x ISSN (p) 2455-0450

crossref DOI: https://dx.doi.org/10.18535/jmscr/v7i12.72

Journal Of Medical Science And Clinical Research

IGM Publication

An Official Publication of IGM Publication

\title{
Role of Ultrasonography and Color Doppler in the Evaluation of Thyroid Lesions with Histopathological Correlation
}

\author{
Authors \\ Dr Sana Afsar ${ }^{1 *}$, Dr Suresh Kumar Toppo², Dr Rajeev Kumar Ranjan ${ }^{3}$, \\ Dr Sunil Kumar Mahto \\ ${ }^{1}$ Junior Resident, Department of Radiology, RIMS Ranchi \\ ${ }^{2}$ Professor \& HOD, Department of Radiology, RIMS Ranchi \\ ${ }^{3}$ Associate Professor, Department of Radiology, RIMS Ranchi \\ ${ }^{4}$ Associate Professor, Department of Pathology, RIMS Ranchi \\ *Corresponding Author \\ Dr Sana Afsar
}

Address: Lake Side, Old Commissioner's Compound, Near Brojendra Palace, Ranchi 834001, India

\begin{abstract}
Thyroid lesions often cause unnecessary patient anxiety and lead to financial burden on patients who undergo invasive tests for clinically unimportant lesions. USG with Doppler interrogation is a noninvasive method of selecting the most suspicious lesion (on the basis of USG features) by avoiding needless biopsies for every nodule. The study aims at assessing the role of USG and Color Doppler in the risk stratification of thyroid lesions based on standard lexicon: ACR-TIRADS 2017 and correlating findings with histopathological examination. Secondly, guiding decision whether to perform FNAC/biopsy or follow up by interval USG. Thirdly, in improving prognosis and survival rate by detecting malignancy at an early stage. 125 adult patients with thyroid lesions were evaluated from March 2018 to August 2019 with ultrasonography and color Doppler and categorized as per ACR-TIRADS 2017 classification. The results in each TIRADS category were compared with histopathological examination. Combining TIRADS 2 and 3 as probably benign ultrasound findings and TIRADS 4 and 5 as probably malignant, sensitivity, specificity, positive predictive value, negative predictive value and accuracy were $96.8 \%, 63.9 \%, 73.8 \%$, $95.0 \%$ and $80.8 \%$ respectively for TIRADS classification when compared with the cytohistopathological results. Doppler findings of intranodular /central/ central > peripheral pattern of vascularity favouring malignancy correlated well with histopathological results. Thus, USG can be used as a reliable modality for early detection of thyroid lesions and in excluding malignancy thereby obviating costly interventions for nodules that can be safely followed up by interval USG.
\end{abstract}

Keywords: USG, Thyroid lesions, Color Doppler, ACR TIRADS 2017, FNAC, Histopathological.

\section{Introduction}

Thyroid lesions are a commonly encountered disease entity in our clinical practice and often lead to costly interventions for most nodules that ultimately prove benign. ${ }^{[1]}$ Majority of thyroid nodules cannot be picked up on palpation . Studies show that with palpation nodules can be detected in only $5 \%$ cases. $^{2}$ USG being more sensitive compared to palpation can discover nodules in up to $67 \%$ of the general population. ${ }^{[2]}$ 
Asssociated cervical lymphadenopathy, the presence of additional nodules if any, can also be observed on USG in addition to accurate nodule size for interval follow up and Fine needle aspiration cytology (FNAC) guidance when needed.

Based on the USG findings and cytology from FNA, the clinician can decide whether surgical excision of a thyroid nodule is required.

Various USG features of thyroid lesions in combination, such as solid/ predominantly solid composition, marked hypoechogenicity, lobulated margins, punctuate echogenic foci and taller than wide shape, favour malignancy. ${ }^{[3]}$

Use of color Doppler imaging helps to establish the vascular pattern of thyroid nodules. A statistically significant positive association with thyroid malignancy $(\mathrm{p}<0.05)$ has been noted with internal or intranodular vascular pattern. ${ }^{[4]}$ As per a meta analysis, intranodular vascularity is a moderate predictor of malignancy with an odds ratio of $4.3 .^{[5]}$

There has been a radical change in the management of patients with nodular lesions with the application of FNAC or biopsy. FNAC is considered as a safe, accurate and cost effective diagnostic method for distinguishing between benign and malignant nodules. Under USG guidance there has been a significant reduction in the number of inadequate fine needle aspirates or biopsies. ${ }^{[6]}$

\section{Materials and Method}

Study Design: The study was an Institution based prospective type of observational study. Consecutive type of non probability sampling was used for selection of study subjects.

Study Period was from March 2018 to Aug 2019. Sample Size: 125 adult outdoor patients with thyroid lesions referred to Department of Radiodiagnosis at Rajendra Institute of Medical sciences (RIMS), Ranchi were evaluated with ultrasonography, color Doppler and appropriate pathological examination.. Descriptive and inferential method of statistical analysis has been carried out in the present study. To evaluate the significance of various parameters used in the study, Chi-square/ Fisher Exact test has been used. A p-value of $<0.05$ has been considered statistically significant.

Significant figures

( $\mathrm{P}$ value: $0.05<\mathrm{P}<0.10$ ) is of + suggestive significance

( $\mathrm{P}$ value: $0.01<\mathrm{P}<0.05)$ is of $*$ moderate significance

( $\mathrm{P}$ value: $\mathrm{P}<0.01)$ is $* * *$ of strong significance

\section{Statistical software}

The Statistical software that have been used for data analysis are SPSS 15.0, Systat 12.0, MedCalc 9.0.1, SAS 9.2, Stata 10.1 and $\mathrm{R}$ environment ver.2.11.1 and Microsoft word and Excel have been used to construct graphs, tables etc.

Inclusion Criteria (i) All adult outdoor patients with clinically suspected thyroid lesions. (ii).Thyroid lesions incidentally detected on USG.

Exclusion Criteria (i) Neck swelling other than thyroid. (ii) Diffuse thyroid disease without nodules. (iii) Pediatric patients. (iv) Non cooperative patients (v) Post operative and post radiotherapy cases (vi) Patients having bleeding disorders.

\section{Techniques and Tools \\ Informed consent}

Informed consent has been obtained from all the patients after explaining them the procedure proposed and the possible complications that may arise from the same, in a language best understood by them.

Procedure: Patients with suspected thyroid lesions were subjected to ultrasound and color doppler imaging on Philips ultra HD II XE using a high frequency, 7.5-12 MHz, linear transducer and confirmation was done with FNAC.

In FNAC inconclusive cases biopsy was done for confirmation. In patients with normal ultrasonogaphy, further evaluation was not done.

FNAC was done with all aseptic precautions under ultrasound guidance with $0.55 \times 25 \mathrm{~mm}$ 
needle and 2cc or 5cc syringe. At least four smears were prepared for each patient. Two smears were instantly fixed using 95\% ethanol and stained with Papanicolaou (Pap) stain, remaining two were air dried prior to staining with May Grunwald Giemsa (MGG stain.) The smears were then examined by a cytopathologist .Final diagnosis was given based on cell morphology.

\section{Core Needle Biopsy ${ }^{[7,8]}$}

Local anesthesia is used prior to this procedure. Core-needle biopsy has a high diagnostic yield and accuracy and is well tolerated with low incidence of complications.USG and color Doppler findings were correlated with" gold standard" i.e histopathological findings .

\section{American College of Radiology: Thyroid Imaging Reporting and Data System (ACR TIRADS 2017) ${ }^{[\mathbf{9 , 1 0 ]}}$}

Based on the five categories of USG findings (table I), scoring is done. If the cumulative score is high the TIRADS level and likelihood of malignancy becomes high. From each of the following categories one score is assigned:

Table I: ACR TIRADS 2017 Classification

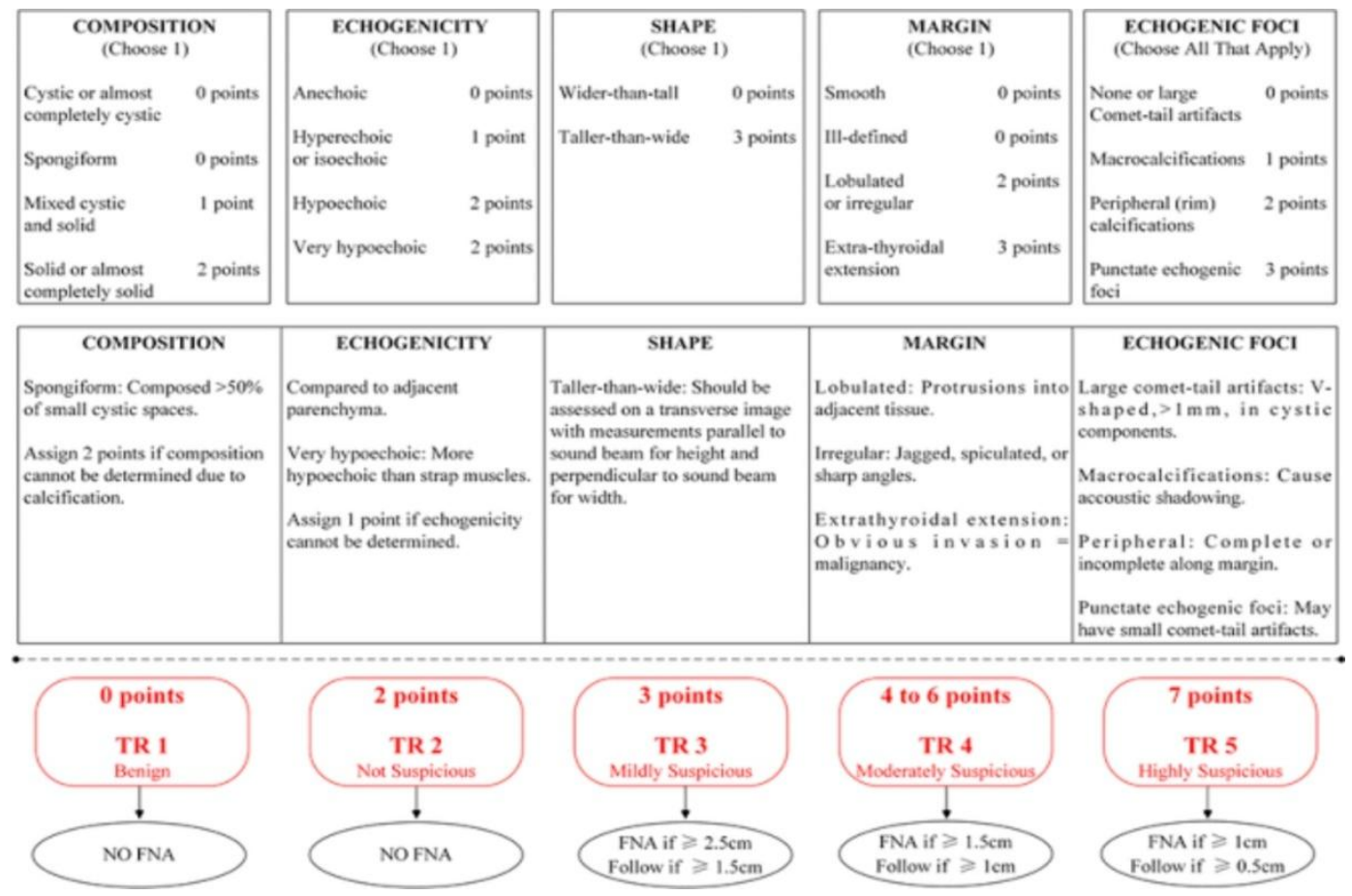

The above findings are given in detail in the 2015 ACR publication. ${ }^{[10]}$

Nodules are measured in three dimensions, however maximum dimension determines whether nodule must be followed up or biopsied (as per table II) .Biopsy is recommended for suspicious lesions belonging to TIRADS 3 to TIRADS 5 categories with the above size criteria. If there are multiple nodules, two nodules with the highest TIRADS grades should be subjected to FNAC/biopsy (rather than the two largest).

Table II: Recommendations For Follow UP ${ }^{[9]}$

\begin{tabular}{|l|l|}
\hline $\begin{array}{l}\text { TIRADS } \\
\text { category }\end{array}$ & Timing of follow up/fnac \\
\hline $\mathbf{1}$ & no FNA needed \\
\hline $\mathbf{2}$ & no FNA needed \\
\hline $\mathbf{3}$ & if $\geq 1.5 \mathrm{~cm}$ follow up, if $\geq 2.5 \mathrm{~cm}$ FNA (follow up at $: 1,3$ and 5 years) \\
\hline $\mathbf{4}$ & if $\geq 1.0 \mathrm{~cm}$ follow up, if $\geq 1.5 \mathrm{~cm}$ FNA (follow up at $: 1,2,3$ and 5 years) \\
\hline $\mathbf{5}$ & if $\geq 0.5 \mathrm{~cm}$ follow up, if $\geq 1.0 \mathrm{~cm}$ FNA (annual follow up for up to 5 years) \\
\hline
\end{tabular}




\section{JMSCR Vol||07||Issue||12||Page 391-398||December}

Significant interval enlargement on follow up refers to "increase of $20 \%$ and $2 \mathrm{~mm}$ in two dimensions, or a $50 \%$ increase in volume". If the TIRADS level increases between scans, an interval scan is recommended the following year. $^{[9]}$
Doppler flow pattern is not included in ACR TIRADS 2017 as the current generation of Doppler instruments which are extremely sensitive to blood flow, have resulted in considerable overlap in intranodular vascularity between benign and malignant lesions. ${ }^{[11]}$

\section{Results}

The final analysis is presented in the form of the following tables/graphs

Table III: Age distribution of patients in relation to Benign and Malignant cases

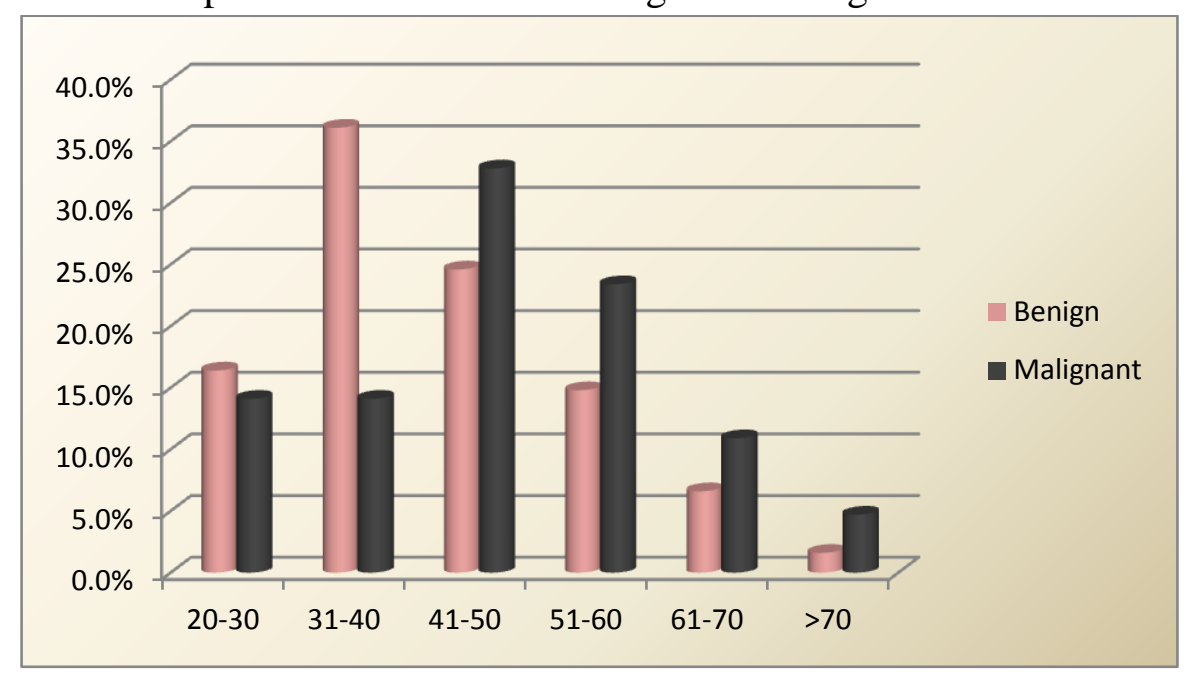

Table IV: Gender distribution of patients in relation to Benign and Malignant cases

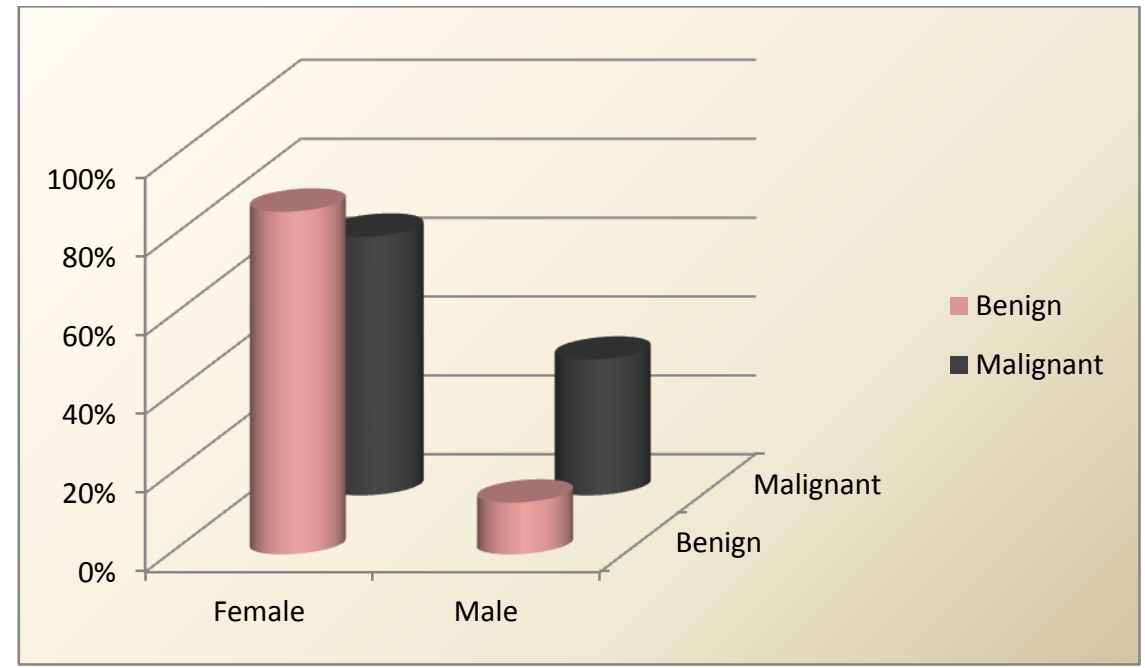

Table V: Distribution of TIRADS in relation to Benign and Malignant cases

\begin{tabular}{l|c|c|c|}
\hline \multirow{2}{*}{ TIRADS } & \multicolumn{2}{|c|}{ Final Diagnosis } & \multirow{2}{*}{ Total } \\
\cline { 2 - 3 } & BENIGN & MALIGNANT & \\
\hline 1 & $0(0 \%)$ & $0(0 \%)$ & $0(0 \%)$ \\
\hline 2 & $16(26.2 \%)$ & $0(0 \%)$ & $16(12.8 \%)$ \\
\hline 3 & $23(37.7 \%)$ & $2(3.1 \%)$ & $25(20.0 \%)$ \\
\hline 4 & $22(36.1 \%)$ & $22(34.4 \%)$ & $44(35.2 \%)$ \\
\hline 5 & $0(0 \%)$ & $40(62.5 \%)$ & $40(32.0 \%)$ \\
\hline Total & $61(100 \%)$ & $64(100 \%)$ & $125(100 \%)$ \\
\hline
\end{tabular}


Among TIRADS categories studied all TIRADS 2, most of the TIRADS 3 nodules proved to be benign whereas about $50 \%$ of TIRADS 4 and all of TIRADS 5 nodules were proved to be malignant.

Table VI: Comparison of TIRADS with FNAC/biopsy

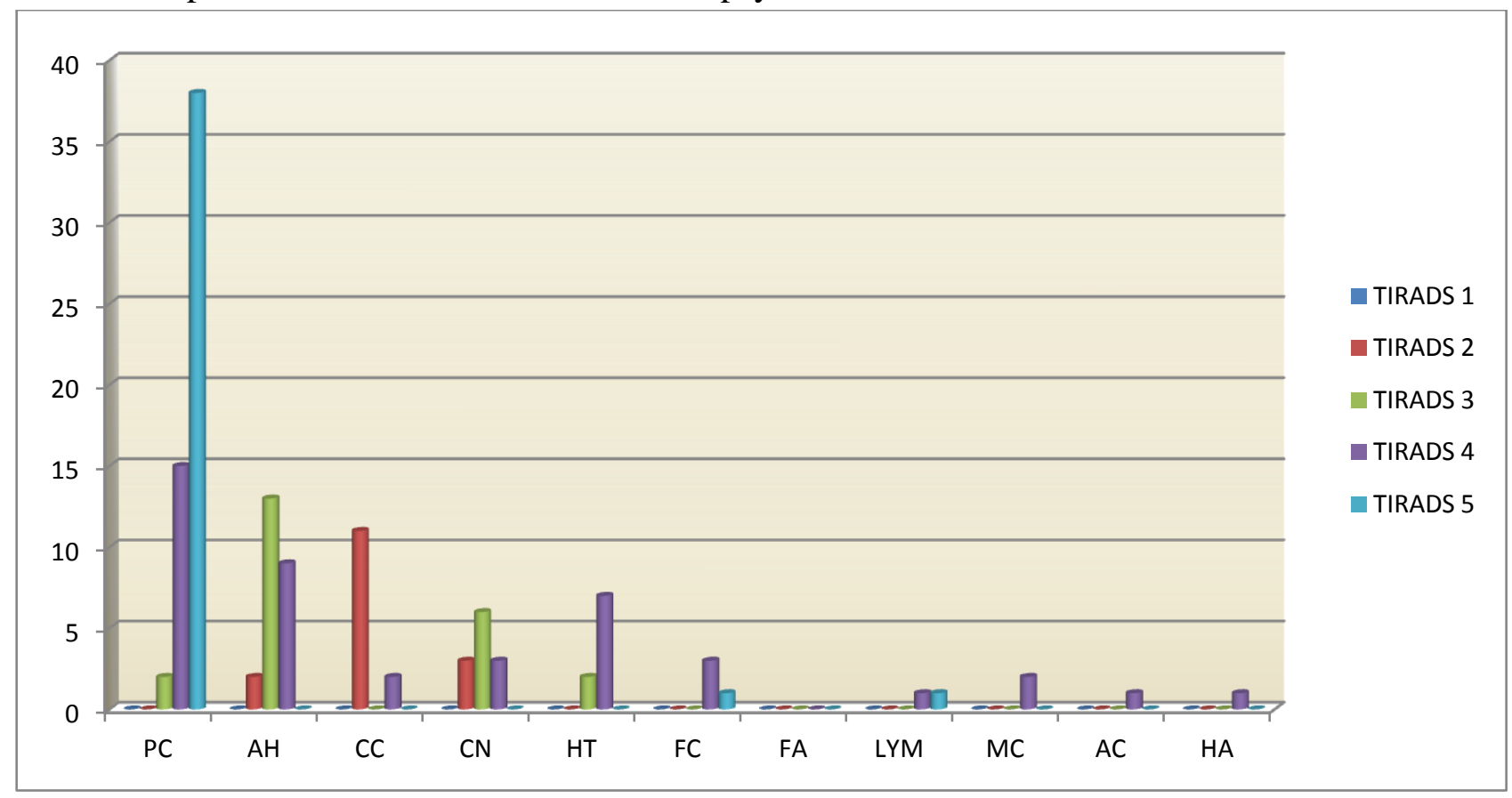

Among TIRADS categories studied all TIRADS 2 nodules proved to be benign which included Adenomatous hyperplasia, $(\mathrm{AH})$, Hashimotos thyroiditis (HT,)colloid cyst(CC), colloid nodule (CN) and Hurthe adenoma(HA).whereas all TIRADS 5 and $50 \%$ of TIRADS 4 proved to malignant nodules which included Papillary ca, (PC) Follicular ca(FC), Medullary ca(MC), Anaplastic ca(AC) and Lymphoma.(LYM) In TIRADS 3 most of the nodules were benign except two nodules that were proved to be malignant (papillary ca $=\mathrm{PC}$ )
Table no VII: Distribution of vascularity in thyroid lesions in relation with Benign and Malignant cases

\begin{tabular}{|l|c|c|c|}
\hline \multirow{2}{*}{ Vascularity } & \multicolumn{2}{|c|}{ Final Dignosis } & \multirow{2}{*}{ Total } \\
\cline { 2 - 3 } & BENIGN & Malignant & \\
\hline $\mathrm{A}$ & $8(13.1 \%)$ & $46(71.9 \%)$ & $54(43.2 \%)$ \\
\hline $\mathrm{B}$ & $53(86.9 \%)$ & $18(28.1 \%)$ & $71(56.8 \%)$ \\
\hline Total & $61(100 \%)$ & $64(100 \%)$ & $125(100 \%)$ \\
\hline
\end{tabular}

$\mathrm{P}<0.001^{* *}$, Significant, Chi-Square test

A- central/intranodular $>$ perinodular pattern of vascularity. B- Absent / perinodular / perinodular > central/intranodular pattern of vascularity.

Table VIII: Diagnostic accuracy of USG findings for malignant thyroid lesions

\begin{tabular}{|c|c|c|c|c|c|c|c|c|c|c|c|}
\hline \multirow{2}{*}{ Variables } & \multicolumn{5}{|c|}{ Observation } & \multicolumn{6}{|c|}{ Correlation } \\
\hline & TP & FP & FN & $\mathbf{T N}$ & Total & Se & Sp & PPV & NPV & Accuracy & $P$ value \\
\hline $\mathrm{T}>\mathrm{W}$ & 50 & 11 & 14 & 50 & 125 & 78.11 & 81.97 & 81.97 & 78.13 & 80.00 & $<0.001 * *$ \\
\hline IRR/ETE & 43 & 2 & 21 & 59 & 125 & 67.19 & 96.72 & 95.56 & 73.75 & 81.60 & $<0.001 * *$ \\
\hline SOLID & 49 & 25 & 15 & 36 & 125 & 76.56 & 60.66 & 67.12 & 71.15 & 68.80 & $<0.001 * *$ \\
\hline VAS & 46 & 8 & 18 & 53 & 125 & 71.9 & 86.9 & 85.2 & 74.7 & 79.2 & $<0.001 * *$ \\
\hline MICRO & 38 & 1 & 26 & 60 & 125 & 60.8 & 98.4 & 97.5 & 69.7 & 78.6 & $<0.001 * *$ \\
\hline V HYPO & 20 & 1 & 44 & 60 & 125 & 31.3 & 98.36 & 95.24 & 57.69 & 64.00 & $<0.001 * *$ \\
\hline TIRADS & 62 & 22 & 2 & 39 & 125 & 96.8 & 63.9 & 73.8 & 95.0 & 80.8 & $<0.001 * *$ \\
\hline
\end{tabular}

T>W: Taller than wide IRR/ETE: Irregular margins/extrathyroidal extension VAS Intranodular/central vascularity MICRO: Microcalcification/Punctate ehogenic foci V.HYPO: Very Hypoehoic TP: True positive FP: False positive FN:False negative TN:True negative Se: Sensitivity Sp:Specificity PPV/NPV:Positive/Negative predictive value 
Table no IX: Comparison of Doppler parameters in determination of malignancy in thyroid nodules

\begin{tabular}{|c|c|c|c|}
\hline \multirow[t]{2}{*}{ CHARACTERISTIC } & Moon et al ${ }^{[11]}(2010)$ & $\begin{array}{c}\text { Chammas et } \mathbf{a l}^{[12]} \\
(2005)\end{array}$ & $\begin{array}{c}\text { Present Study } \\
(2018-19)\end{array}$ \\
\hline & p VALUE & p VALUE & p VALUE \\
\hline $\begin{array}{l}\text { Central/intranodular> } \\
\text { peripheral/perinodular vascularity }\end{array}$ & $<0.0001$ & $<0.001$ & $<0.001$ \\
\hline
\end{tabular}

Table no X: Comparison of diagnostic indices of TIRADS classification.

\begin{tabular}{|l|c|c|c|c|c|}
\hline \multirow{2}{*}{ STUDY } & \multicolumn{5}{|c|}{ TIRADS } \\
\cline { 2 - 6 } & $\begin{array}{c}\text { Sensitivity } \\
\text { (in \%) }\end{array}$ & $\begin{array}{c}\text { Specificity } \\
\text { (in \%) }\end{array}$ & $\begin{array}{c}\text { Positive } \\
\text { Predictive } \\
\text { Value (in \%) }\end{array}$ & $\begin{array}{c}\text { Negative } \\
\text { Predictive } \\
\text { Value (in \%) }\end{array}$ & $\begin{array}{c}\text { Accuracy } \\
\text { (in \%) }\end{array}$ \\
\hline Horvath et al $^{[13]}(\mathbf{2 0 0 9 )}$ & 88 & 49 & 49 & 88 & 94 \\
\hline Moifo et al $^{[14]}(\mathbf{2 0 1 3})$ & 98.3 & 52.17 & 97.32 & 60 & 95.58 \\
\hline Russ et al $^{[15]} \mathbf{( 2 0 1 3 )}$ & 95.7 & 61 & - & 99.7 & 62 \\
\hline Present Study (2018-19) & 96.88 & 63.9 & 73.8 & 95 & 80.8 \\
\hline
\end{tabular}

\section{Summary}

The present study "Role of ultrasonography and color Doppler in the evaluation of thyroid lesions with histopathological correlation" was undertaken in the Department of Radio diagnosis, at RIMS, Ranchi over a period of eighteen months.

A total of 125 patients were enrolled in the study with written and informed consent.

Patients underwent USG and color Doppler examination followed by FNAC/biopsy.

Age range was from 20 to 74 years. There were 95 (76\%) females and 30 (24\%) males with a female : male ratio of 3.2:1. Pathologically, 64 lesions were malignant and 61 were benign.

The incidence of both benign and malignant lesions was more in female patients, but the probability of malignant nodule was more in male with malignant to benign thyroid lesion ratio in male being $2.75: 1$ and that in female being 1:1.26.

USG features -“ taller than wide shape”, irregular margins or lesions extending outside thyroid, very hypoechoic texture, punctate echogenic foci, solid composition, intranodular vs perinodular pattern of vascularity and associated cervical lymphadenopathy suggested malignancy. Likewise the presence of Wider than tall shape, smooth margins/ ill defined margins, perinodular>intranodular pattern of vascularity, isoehoic or hyperechoic texture, cystic or spongiform composition and macrocalcification suggested benignity.

Sensitivities for USG findings suggestive of malignancy " taller than- wide shape", lobulated or irregular margins or extension outside thyroid, marked hypo echogenicity, punctuate echogenic foci, solid composition ,were $78.11 \%, 67.19 \%$, $82.8 \%, 31.3 \%, 60.8 \%$ and $76.56 \%$ respectively. Specificities were $81.97 \%, 96.72 \%, 70.49 \%$, $98.36 \% \quad 98.4 \%$ and $60.6 \%$ respectively. Diagnostic accuracies were $80 \%, 81.60 \%, 76.8 \%$, $64 \%, 78.6 \%$ and $68.8 \%$ respectively.

Sensitivity for color Doppler findings of intranodular > perinodular pattern of vascularity predicting malignancy was $71.9 \%$ and specificity and diagnostic accuracy was $86.9 \%, 79.2 \%$ respectively.

\section{Discussion}

Ultrasonography with color Doppler interrogation has been found to be a highly reliable diagnostic imaging study in the evaluation of thyroid lesion. ACR-TIRADS 2017 classification is highly sensitive, accurate, can reliably exclude malignancy in thyroid lesions and can be easily used in reporting and interpreting thyroid lesions.

\section{Limitations of the Study}

(i) The duration of the study was for a shorter period (18 months). (ii) Since our hospital runs central government schemes, the significant pool 
of patients coming to the hospital are from poor socioeconomic group, hence the disease was already in an advanced stage in some cases and the likelihood of malignancy was on higher side.(iii) Hospital being provided with separate oncology wing and majority of references coming to radiology for thyroid USG were from oncology department, the number of malignant lesions encountered were more than benign lesions. (iv) Pediatric cases were not included, so usefulness of USG and color Doppler features in those patients were not evaluated.

\section{References}

1. Brander AE, Viikinkoski VP, Nickels JI, Kivisaari LM. Importance of thyroid abnormalities detected at US screening: a 5-year follow-up._ Radiology. 2000 Jun;215

(3):801-6. doi: 10.1148/radiology.215.3.r00jn07801.

2. Russ G, Leboulleux S, Leenhardt L, Hegedüs L. Thyroid incidentalomas: epidemiology, risk stratification with ultrasound and workup. Eur Thyroid J. 2014 Sep;3(3):154-63. doi: $10.1159 / 000365289$.

3. Kwak JY, Han KH, Yoon JH, Moon HJ, Son EJ, Park SH, Jung HK, Choi JS, Kim BM, Kim EK. Thyroid imaging reporting and data system for US features of nodules: a step in establishing better stratification of cancer risk._Radiology. $2011 \quad$ Sep;260(3):8929. doi: 10.1148/radiol.11110206.

4. Wettasinghe MC, Rosairo S, Ratnatunga $\mathrm{N}$, Wickramasinghe ND. Diagnostic accuracy of ultrasound characteristics in the identification of malignant thyroid nodules. BMC Res Notes. 2019 Apr 2;12(1):193. doi: $\quad$ 10.1186/s13104-0194235-y.

5. Woliński K, Szkudlarek M, SzczepanekParulska E, Ruchała M. Usefulness of different ultrasound features of malignancy in predicting the type of thyroid lesions: a meta-analysis of prospective studies. Pol Arch Med Wewn. 2014;124(3):97104. doi: 10.20452/pamw.2132.

6. Bagga PK, Mahajan NC. Fine needle aspiration cytology of thyroid swellings: how useful and accurate is it?. Indian J Cancer. 2010 Oct-Dec;47(4):437-42. doi: 10.4103/0019-509X.73564.

7. Hahn SY, Shin JH, Han BK, Ko EY, Ko ES. Ultrasonography-guided core needle biopsy for the thyroid nodule: does the procedure hold any benefit for the diagnosis when fine-needle aspiration cytology analysis shows inconclusive results?. Br J Radiol. 2013 May;86 (1025): 20130007. doi: 10.1259/bjr.20130007.

8. Samir AE, Vij A, Seale MK, Desai G, Halpern E, Faquin WC, Parangi S, Hahn PF, Daniels GH. Ultrasound-guided percutaneous thyroid nodule core biopsy: clinical utility in patients with prior nondiagnostic fine-needle aspirate. Thyroid. 2012 May;22(5):4617. doi: 10.1089/thy.2011.0061.

9. Tessler FN, Middleton WD, Grant EG, Hoang JK, Berland LL, Teefey SA, Cronan JJ, Beland MD, Desser TS, Frates MC, Hammers LW, Hamper UM, Langer JE, Reading CC, Scoutt LM, Stavros AT. ACR Thyroid Imaging, Reporting and Data System (TI-RADS): White Paper of the ACR TI-RADS Committee. J Am Coll Radiol. 2017 May;14(5):587-595. doi: 10.1016/j.jacr.2017.01.046.

10. Grant EG, Tessler FN, Hoang JK, Langer JE, Beland MD, Berland LL, Cronan JJ, Desser TS, Frates MC, Hamper UM, Middleton WD, Reading CC, Scoutt LM, Stavros AT, Teefey SA. Thyroid Ultrasound Reporting Lexicon: White Paper of the ACR Thyroid Imaging, Reporting and Data System (TIRADS) Committee. J Am Coll Radiol. 2015 Dec;12(12 Pt A):1272-9. doi: 10.1016/j.jacr.2015.07.011. 
11. Moon HJ, Kwak JY, Kim MJ, Son EJ, Kim EK. Can vascularity at power Doppler US help predict thyroid malignancy?. Radiology. 2010

Apr;255(1):260-9. doi: 10.1148/radiol.09091284.

12. Chammas MC, Gerhard R, de Oliveira IR, Widman A, de Barros N, Durazzo M, Ferraz A, Cerri GG. Thyroid nodules: evaluation with power Doppler and duplex Doppler ultrasound. Otolaryngol Head Neck Surg. 2005 Jun;132(6):874-82. doi: 10.1016/j.otohns.2005.02.003

13. Horvath E, Majlis S, Rossi R, Franco C, Niedmann JP, Castro A, Dominguez M. An ultrasonogram reporting system for thyroid nodules stratifying cancer risk for clinical management. J Clin Endocrinol Metab. 2009 May;94(5):1748-51. doi: 10.1210/jc.2008-1724.

14. Moifo B, Takoeta E, Tambe J, Blanc F, Fotsin J. Reliability of Thyroid Imaging Reporting and Data System (TIRADS) Classification in Differentiating Benign from Malignant Thyroid Nodules. Open Journal of Radiology. 2013;03(03):103107.

15. Russ G, Royer B, Bigorgne C, Rouxel A, Bienvenu-Perrard M, Leenhardt L. Prospective evaluation of thyroid imaging reporting and data system on 4550 nodules with and without elastography. European Journal of Endocrinology. 2013;168(5):649-655. 